\title{
Persepsi Dokter Puskesmas di Kota Bandung terhadap Implementasi Sistem Jaminan Kesehatan Nasional
}

\author{
Aldi Harry Ramdani, ${ }^{1}$ Elsa Pudji Setiawati, ${ }^{2}$ Dewi Marhaeni Diah Herawati, ${ }^{2}$ \\ ${ }^{1}$ Fakultas Kedokteran Universitas Padjadjaran \\ ${ }^{2}$ Departemen Ilmu Kesehatan Masyarakat, Fakultas Kedokteran, Universitas Padjadajaran
}

\begin{abstract}
Abstrak
Perubahan pembayaran pelayanan kesehatan dari sistem fee for service menjadi sistem kapitasi dan perubahan potensi pendapatan dokter puskesmas menimbulkan berbagai persepsi. Penelitian ini bertujuan untuk menggali persepsi dokter puskesmas tentang sistem pembiayaan kapitasi dan potensi pendapatan yang diterima pada era implementasi Jaminan Kesehatan Nasional (JKN). Desain penelitian adalah kualitatif, purposive sampling. Penelitian dilakukan pada bulan September - November 2015 dengan populasi dokter puskesmas di Provinsi Jawa Barat. Kriteria inklusi adalah dokter puskesmas yang bekerja di puskesmas dengan gawat darurat 24 jam, sudah bekerja minimal 2 tahun di puskesmas, dan bersedia diwawancara. Pengumpulan data dengan wawancara mendalam semi terstruktur. Analisis data dengan teknik content analysis. Persepsi dokter puskesmas tentang sistem JKN meliputi tiga hal, sistem JKN merupakan sistem dengan mekanisme asuransi sosial, bermanfaat dalam perlindungan kesehatan masyarakat, dan sosialisasi yang masih minim. Pembayaran kapitasi yang diterima tidak mengubah pelayanan yang diberikan oleh dokter puskesmas. Semakin besar jumlah pasien yang dirujuk akan mengurangi besarnya kapitasi yang diterima. Pembayaran yang diterima oleh dokter puskesmas mengalami keterlambatan. Persepsi dokter puskesmas telah memahami tentang sistem JKN, masih terdapat keluhan, yaitu sosialisasi yang kurang dan keterlambatan pembayaran kapitasi. Permasalahan ini membutuhkan peningkatan sosialisasi dan pengkajian ulang tentang sistem kapitasi.
\end{abstract}

Kata Kunci: Dokter puskesmas, Persepsi, Potensi pendapatan, Sistem Kapitasi

\section{Perception of Primary Physician in Bandung Towards Universal Health Coverage Implementation}

\begin{abstract}
Changes in health-care payment methods from fee for service into capitation system and changes in primary physician's income potential lead to various perceptions. This study aimed to explore the primary physician's perception about the capitation system and income potential in the Universal Health Coverage (UHC) system. The studydesign was descriptive qualitative, purposive sampling. It was conducted from September to November 2015 with study population were primary physicians in West Java. The inclusion criteria were the primary physician working in primary care with 24-hour emergency services, has worked at least 2 years in the primary care, and agreed to be interviewed. Data collection was conducted using in-depth interview. Data analysis was conducted using content analysis.Primary physician's perception about UHC system were the system that used social insurance mechanism, beneficial for society health protection, and the socialization were still minimal. Capitation payment received by the primary physician did not change the given services. The greater the amount of referred patients will reduce the amount of capitation received. The payment received by the primary physician has been delayed. Primary physician's perception has understood about the UHC system, with complaints about the lack of socialization and the delay in capitation payment. These problems required increase in socialization and re-assessment about the capitation system.
\end{abstract}

Keywords: Capitation system, Income potential, Perception, Primary Physician

Korespondensi:

Aldi Harry Ramdani

Fakultas Kedokteran Universitas Padjadjaran

Jl. Prof. Dr. Eyckman No. 38 Bandung 40161

Mobile : 085716580907

Email : aldiharry@gmail.com 


\section{Pendahuluan}

Sistem Jaminan Kesehatan Nasional (JKN) adalah sistem kesehatan yang penerapannya menggunakan mekanisme asuransi kesehatan sosial atau subsidi silang yang bersifat wajib dengan tujuan untuk menjamin perlindungan kesehatan masyarakat. ${ }^{1}$ Dokter puskesmas merupakan dokter yang bekerja pada pusat pelayanan kesehatan tingkat pertama yang memiliki peranan yang sangat penting dalam era sistem JKN sebagai lapisan terbawah dalam piramida kesehatan ideal dan garda terdepan dimana terjadi kontak pelayanan kesehatan pertama dengan perorangan atau kelompok. ${ }^{2}$

Sistem pembayaran jasa medis dokter puskesmas berubah dari sistem fee for service menjadi sistem Kapitasi. Sistem Kapitasi adalah metode pemberian kompensasi jasa medis di muka dengan nilai tetap per peserta per bulan. Sistem ini bertujuan untuk mengedepankan prinsip pelayanan promotif dan preventif kepada pasien. Potensi pendapatan dokter puskesmas dalam setahun adalah hasil dari perkalian antara produktivitas dokter dengan jasa medis. Jasa medis merupakan kompensasi atas suatu layanan medis yang diberikan kepada dokter puskesmas. Proporsi waktu ideal seorang dokter puskesmas adalah $80 \%$ untuk tatap muka melayani pasien, dan 20\% untuk kegiatan lain. Era JKN, peningkatan produktivas kerja seorang dokter puskesmas sangat mempengaruhi potensi pendapatan yang diterima. ${ }^{3}$ Sistem JKN menimbulkan berbagai persepsi dari berbagai pihak yang terlibat langsung, yaitu pemerintah sebagai stakeholder, dokter sebagai tenaga medis, maupun masyarakat sebagai konsumen. Penelitian ini bertujuan untuk mendapatkan gambaran yang lebih jelas mengenai persepsi dokter puskesmas di kota Bandung terhadap implementasi sistem JKN.

\section{Metode}

Metode penelitian ini adalah kualitatif, dengan populasi adalah dokter puskesmas di Kota Bandung. Teknik pemilihan sampel menggunakan teknik purposive sampling. Subjek penelitian yang terpilih adalah 6 dokter fungsional yang bekerja di puskesmas dengan fasilitas gawat darurat 24 jam di Kota Bandung (Puskesmas Padasuka, Puskesmas Puter, Puskesmas Kopo, Puskesmas Pagarsih, Puskesmas Garuda, dan Puskesmas Ibrahim Adjie). Puskesmas yang dipilih berdasarkan estimasi penduduk tertinggi pada setiap puskesmas di Kota Bandung. Kriteria inklusi adalah dokter puskesmas yang telah bekerja selama minimal 2 tahun dan bersedia untuk diikutsertakan ke dalam penelitian. Kriteria eksklusi adalah dokter puskesmas yang tidak bersedia diikutsertakan ke dalam penelitian. Penelitian ini sudah disetujui oleh Komite Etik Penelitian Kesehatan Fakultas Kedokteran Universitas Padjadjaran dengan surat No. 432/ UN6.C1.3.2/KEPK/PN/2015.

Teknik pengumpulan data menggunakan teknik wawancara mendalam menggunakan panduan wawancara semi-terstruktur. Pedoman wawancara dikembangkan dari buku pedoman Monev Program Jaminan Kesehatan 2015. Responden mendapatkan penjelasan mengenai tujuan, aspek kerahasiaan, dan topik wawancara. Wawancara mendalam berlangsung selama 15-30 menit dibantu dengan alat perekam dan catatan kecil. Setelah proses wawancara selesai, dilakukan konfirmasi ulang mengenai poin-poin yang telah dicatat dalam catatan kecil. Rekaman suara dari wawancara ditranskripsi ke dalam bentuk teks kemudian direduksi. Hasil reduksi dilakukan analisis dengan menggunakan metode analisis konten dibantu oleh expert judgement. Proses analisis meliputi koding data untuk mendeskripsikan kategori-kategori dan tematema. Hasil analisis data ditampilkan dalam bentuk deskripsi dan tema-tema yang akan disajikan kembali ke dalam narasi. Langkah terakhir adalah melakukan interpretasi atau memaknai data. ${ }^{4}$

\section{Hasil}

Jumlah responden yang diikutsertakan ke dalam penelitian berjumlah 6 orang dokter puskesmas. Karakteristik responden yang diikutsertakan dalam penelitian ditunjukan pada tabel 1 .

Responden memiliki karakteristik yang berbeda-beda dilihat dari status dan jumlah dokter di tempat responden bekerja. Perbedaan status PNS dan PTT membedakan jumlah gaji dan beban kerja pada responden. Responden dengan status PNS mendapatkan dana tambahan selain gaji pokok dan kapitasi, yaitu dana tunjangan daerah. Responden dengan status PNS dalam prakteknya lebih dilibatkan ke berbagai program puskesmas dibandingkan dengan responden berstatus PTT. Responden yang bekerja di puskesmas dengan jumlah dokter fungsional yang lebih sedikit cenderung memilki beban kerja yang lebih banyak.

Berdasarkan hasil wawancara maka, topik wawancara dapat dikelompokkan menjadi tiga tema, kemudian disusun menjadi beberapa kategori dan koding. Topik wawancara dalam panduan wawancara memunculkan jawaban responden yang berulang atau jenuh. 
Tabel 1 Karakteristik Responden

\begin{tabular}{cccccc}
\hline No & Puskesmas & Responden & Status & $\begin{array}{c}\text { Jumlah dokter fungsional } \\
\text { di tempat kerja }\end{array}$ & $\begin{array}{c}\text { Estimasi Penduduk } \\
\text { Sasaran 2015 }\end{array}$ \\
\hline 1 & Puskesmas 1 & TA & PNS & 5 dokter fungsional & 107.698 orang \\
2 & Puskesmas 2 & GC & PNS & 3 dokter fungsional & 131.374 orang \\
3 & Puskesmas 3 & AH & PNS & 4 dokter fungsional & 85.573 orang \\
4 & Puskesmas 4 & AN & PNS & 3 dokter fungsional & 68.764 orang \\
5 & Puskesmas 5 & AR & PTT & 4 dokter fungsional & 97.453 orang \\
6 & Puskesmas 6 & AS & PTT & 5 dokter fungsional & 120.801 orang \\
\hline
\end{tabular}

Hasil jawaban responden mencakup aspek pengetahuan tentang mekanisme, manfaat, dan kekurangan sistem JKN, aspek pembayaran, pelayanan, dan rujukan pada sistem kapitasi, dan aspekpotensi pendapatan yang terdiri dari kunjungan, jam kerja, dan operasional.

Pengetahuan Tentang Mekanisme Sistem JKN; Secara umum, responden menyatakan bahwa sistem JKN adalah sistem kesehatan yang menyerupai sistem asuransi dimana peserta membayar iuran atau premi per bulannya. Bagi masyarakat yang tidak mampu, iurannya dibayarkan oleh pemerintah. Pembayaran iuran dibedakan menjadi tiga kelas sesuai dengan kondisi ekonomi masing-masing peserta

"jadi eеeuu..apa..peserta bayar premi terus udah gitu dengan..euu...beda-beda ya preminya kelas 1, kelas 2, kelas 3, eеuиu....untuk mendapatkan perlindungan kesehatan..gitu. trus ada juga sih yang eeeu...PBI atau penerima bantuan iuran itu ya mereka ga bayar...jadi dibantu oleh pemerintah...gitu (Responden 1)

Responden mengatakan program promotif dan preventif tidak mengalami banyak perubahan, namun terdapat program baru setelah adanya sistem JKN, yaitu program prolanis atau program pengelolaan penyakit kronis. Anggota program prolanis terdiri dari pasien penyakit kronis seperti diabetes dan hipertensi dan memiliki kartu peserta JKN. Responden mengatakan program kendali mutu di puskesmas berlangsung setiap tahun, yaitu akreditasi ISO, sedangkan program kendali mutu yang berlangsung setiap bulan bernama lokakarya bulanan (lokbul). Kedua program kendali mutu berfungsi untuk mengevaluasi setiap program yang ada di puskesmas, termasuk penerapan sistem JKN di puskesmas.

"itu lebih ke arah kita berbicaranya ISO kan, nah itu lebih ke jaminan mutu dari pelayanannya sendiri sih bagaimana, ya pastinya dari mulai mana yang sudah di ISO kan, karena memang baru beberapa yang di ISO kan kayak misalkan." (Responden 5)

Pengetahuan Tentang Manfaat Sistem JKN;
Responden beranggapan bahwa sistem JKN sangat bermanfaat untuk membantu membantu masyarakat miskin untuk dapat berobat ke pelayanan kesehatan tanpa memikirkan masalah biaya. Sistem JKN telah memperbaiki keteraturan jenjang pelayanan kesehatan dengan tidak memperbolehkan masyarakat yang menjadi peserta untuk langsung berobat ke rumah sakit atau fasilitas pelayanan sekunder dan tersier.

"memang pada intinya sih pandangan awalnya baik karena sistemnya ya menjadi ada pelayanan primernya, ada pelayanan sekunder nya dan tersiernya itu sangat jelas, berjenjang." (Responden 5)

Pengetahuan Tentang Kekurangan Sistem JKN; Sosialisasi merupakan kekurangan yang sangat terlihat menurut responden. Beberapa puskesmas mendapatkan sosialisasi langsung dari BPJS dan Dinas Kesehatan dan sosialisasi hanya dilakukan sampai pada tingkat kepala puskesmas. Dokter fungsional sebagai pelayan kesehatan terdepan dengan masyarakat belum mendapatkan sosialisasi yang cukup. Masyarakat sebagai konsumen juga tidak mendapatkan sosialisasi yang cukup, ditandai dengan banyaknya masyarakat yang masih mempertanyakan tentang administrasi dan alur pelayanan di puskesmas. Responden mengeluhkan dengan adanya jaminan kesehatan yang diberikan kepada masyarkat menyebabkan kecenderungan masyarakat untuk lebih memilih dirujuk ke rumah sakit. Menurut responden, banyak masyarakat yang meminta untuk dirujuk ke rumah sakit walaupun keluhannya dapat ditangani di puskesmas.

"kadang kita agak sedikit kurang dihargai gitu, karena udah ada JKN, jadi pengen ke spesialis aja, walaupun sakitnya kemarin cuma conjunctivitis, minta dirujuk, kekeuh." (Responden 4)

Pembayaran Pada Sistem Kapitasi; Gaji kapitasi yang diterima dokter puskesmas dihitung dari poin kerja yang didapat. Dokter umum dan dokter gigi yang bekerja di puskesmas mendapatkan poin 150. Poin kerja membedakan nilai kapitasi dan beban kerja yang didapat 
dokter di puskesmas dibandingkan dengan pegawai lainnya, seperti bidan, perawat, dan staf pelaksana. Nilai kapitasi ditentukan oleh jumlah peserta yang terdaftar di setiap wilayah puskesmas. Puskesmas dengan jumlah peserta yang besar akan mendapatkan kapitasi dengan jumlah yang besar. Responden pada puskesmas dengan jumlah kapitasi yang kecil mengeluhkan ketidaksesuaian jumlah kapitasi dibandingkan dengan jumlah peserta yang terdaftar di wilayah puskesmas. Responden dengan jumlah kapitasi yang kecil mengatakan ada beberapa puskesmas dengan jumlah kapitasi yang besar, tetapi jarang dimanfaatkan oleh peserta.

"eeuu..peserta terdaftarnya sebenernya banyak yang dari PBI gitu, kapitasinya jadi besar padahal puskesmas itu jarang dimanfaatkan masyarakatnya, mungkin kedepannya pada sistem yang lebih baik gitu." (Responden 2)

Seluruh responden menyampaikan bahwa gaji kapitasi yang diterima tidak rutin setiap bulannya. Awal penerapan sistem JKN pada tahun 2014, gaji kapitasi yang diterima dokter puskesmas dibayarkan dalam waktu 8-10 bulan. Setelah evaluasi satu tahun berjalannya sistem JKN, pembayaran gaji kapitasi dilakukan dalam waktu 2-3 bulan sekali dengan jumlah yang berubahubah sesuai dengan jumlah kunjungan pasien.

"kalau sistem kapitasi jujur aja dari waktu 2014 jkn baru muncul, kita dirapel setahun, 8 bulan, sekarang pun dari bulan juni belum, juni juli agustus september.” (Responden 1)

Pelayanan Pada Sistem Kapitasi; Pelayanan yang didapatkan antara pasien JKN dengan pasien non-JKN tidak mengalami perubahan. Menurut responden, implementasi sistem JKN mempengaruhi kedisiplinan kerja dokter di puskesmas. Salah satu poin kapitasi dapat dihitung dari tingkat kehadiran setiap dokter. Gaji kapitasi dokter puskesmas akan dipotong sesuai dengan jumlah ketidakhadiran seseorang setiap bulannya. Hal ini menyebabkan dokter puskesmas menjadi semakin taat kepada peraturan perizinan.

"jadi misalkan nanti dari sistem kehadirannya, atau dateng telat atau apanya, itu ada aturannya, jadi nanti poinnya dikalikan dengan itu gitu, yang paling objektif sih kehadirannya, jadi kalau banyak izinnya, kapitasinya itu berkurang." (Responden 6)

Rujukan Pada Sistem Kapitasi; Secara umum, jumlah rujukan dalam sistem JKN mengalami peningkatan yang tinggi. Jumlah rujukan yang tinggi dapat mengurangi poin penilaian puskesmas menjadi tidak baik dan dapat mengurangi nilai kapitasi yang diperoleh. Menurut responden, banyak pasien tidak mengetahui bahwa masalah yang dikeluhkan dapat ditangani di puskesmas. Pengaruh jaminan kesehatan yang diberikan mengakibatkan jumlah kasus yang sebelumnya tidak terdeteksi karena permasalahan biaya berobat menjadi dapat terdeteksi.

"nah jumlah rujukannya pasti dirasakan sangat banyak, karena banyakfenomena gunung es yang penyakit-penyakit yang tadinya tidak terlihat, misalkan kita berbicara SLE ya itu kasusnya tadinya sangat jarang, tapi ternyata setelah adanya BPJS pasien meningkat." (Responden 5) Menurut responden, sistem rujukan balik pada sistem JKN tidak berjalan dengan baik. Jika tidak terdapat keterangan rujuk balik dari rumah sakit, pasien dengan penyakit kronis yang masih ditangani oleh rumah sakit seharusnya tidak perlu meminta rujukan kembali dari puskesmas. Pasien dengan penyakit kronis yang ditangani di rumah sakit banyak yang meminta rujukan kembali dari puskesmas tiap bulannya.

"sistem rujuk balikjuga belum berjalan, iya kalau setau saya kan aturan bpjs itu kalau misalkan kita ngerujuk pasien, dan pasien itu masih harus ditangani di rumah sakit, harusnya kan terus berobat disana, tanpa harus minta rujukan disini tiap bulannya." (Responden 2)

Kunjungan dan Potensi Pendapatan; Secara umum, jumlah kunjungan pasien mengalami peningkatan setelah implementasi sistem JKN. Peningkatan kunjungan pasien sangat terlihat pada puskesmas dengan jumlah peserta tidak mampu atau penerima bantuan iuran (PBI) yang tinggi. Karakteristik pasien yang datang berobat ke setiap puskesmas secara umum dengan keluhan kontrol penyakit kronis atau pasien resiko tinggi yang meminta rujukan ke rumah sakit.

"eeuu...pasien yang datang penyakit kronis biasanya ya, yang ini nya apa yang rujukannya penyakit kronis biasanya DM ya, hipertensi." (Responden 4)

Jam Kerja dan Potensi Pendapatan; Responden mengatakan tidak ada perbedaan jumlah jam kerja yang diwajibkan setelah implementasi sistem JKN. Perbedaan yang terjadi adalah pada proses input data peserta JKN ke dalam sistem di komputer. Pelayanan pasien juga tidak mengalami perubahan, namun dokter puskesmas seringkali melakukan sosialisasi kepada pasien tentang hak dan kewajiban pasien JKN. Secara umum, responden merasa cukup akan perbandingan dari pendapatan yang diterima dengan jam kerja yang diwajibkan.

"kalau dilihat, dibandingkan dengan sebelumnya, sebenernya lebih banyak untungnya buat kita, ya karena gede sekali yang kita bawa ke rumahnya dalam setiap bulan, kalau kerja tetap masih selesai sampai jam kerja, kalau dulu mah kan kerja udah meriksa ya udah, sekarang kerja jam 12 beres, masukin data ke komputer, itu kerjaannya tambahan." (Responden 3) 
Biaya Operasional dan Potensi Pendapatan; Puskesmas di kota Bandung sampai saat ini belum menggunakan dana kapitasi $40 \%$ untuk operasional puskesmas. Secara umum, responden telah melakukan perencanaan untuk mempersiapkan penggunaan dana operasional. Menurut perhitungan responden, penggunaan dana operasional kemungkinan tidak dapat mencukupi kebutuhan operasional puskesmas.

"kedepannya kita kan harus pakai dana yang dari bpjs itu kan, berarti $10 \%$ nya kan yang untuk obatnya aja, $10 \%$ untuk BHP, $10 \%$ untuk alkes gitu. nah, saya sih eeuu..kalau dikalkulasi sekarang kemungkinan bisa jadi ga cukup." (Responden 2).

\section{Pembahasan}

Persepsi merupakan proses mengolah dan mengorganisir data-data yang ada pada indera

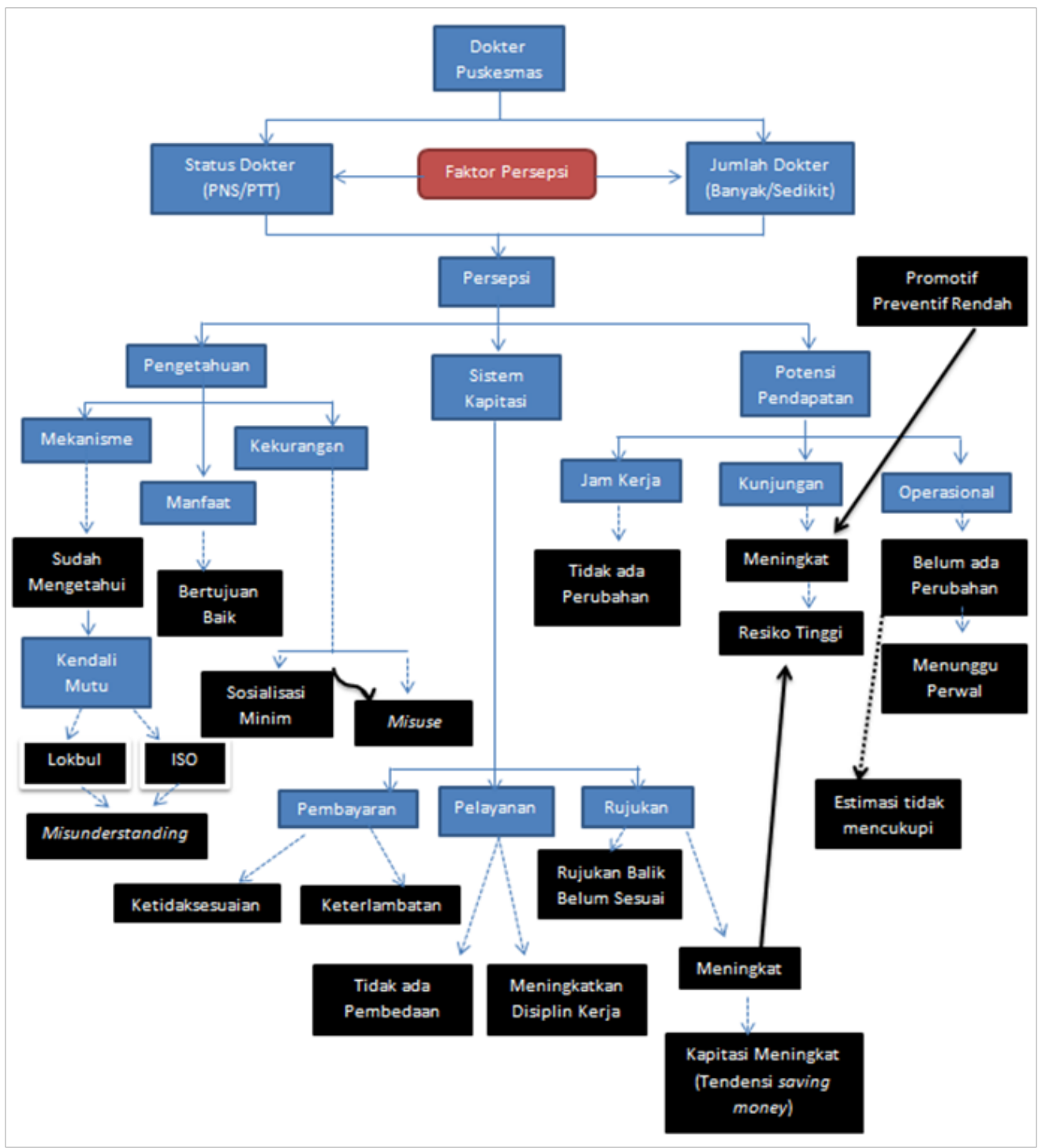

Gambar 1 Peta Konsep Persepsi Dokter terhadap Implementasi Sistem JKN 
individu untuk menyadari lingkungan dan diri individu itu sendiri. Pengaruh lingkungan yang berbeda-beda dapat menimbulkan persepsi yang berbeda. ${ }^{5}$ Persepsi dokter puskesmas terhadap implementasi sistem JKN dapat dijadikan sebagai gambaran dan evaluasimengenaikeberlangsungan sistem JKN di fasilitas kesehatan primer.

Fungsi puskesmas dalam sistem JKN sangat bergantung kepada jumlah tenaga medis seperti dokter didalamnya. Rasio dokter puskesmas di Indonesia tahun 2013 adalah 37,2 per 100.000 penduduk, masih tertinggal apabila dibandingkan dengan negara Kuba dimana 1 dokter melayani 500-700 warga. $^{6}$ Tujuan sistem JKN adalah memperbaiki jenjang pelayanan lebih teratur dan menjamin seluruh masyarakat untuk mendapatkan perlindungan kesehatan pada tahun 2019. ${ }^{7}$

Secara umum, persepsi dokter puskesmas mengenai mekanisme sistem JKN menggunakan asuransi sosial dan sistem yang memberikan perlindungan jaminan kesehatan telah sesuai dengan peraturan pemerintah. ${ }^{1,2}$ Mekanisme asuransi sosialmenggunakan prinsip subsidi silang antara peserta yang mampu dan tidak mampu. ${ }^{8}$ Subsidi silang pada wilayah puskesmas dengan jumlah masyarakat tidak mampu yang besardapat membantu masyarakat tidak mampu untuk dapat berobat tanpa terkendala masalah biaya, namun hal ini juga menyebabkan peningkatan jumlah kunjungan yang tinggi di puskesmas. Kunjungan akan menurun apabila program pelayanan promotif dan preventif di puskesmas telah berjalan dengan baik seperti yang ditunjukan pada penelitian sebelumnya di Yogyakarta. ${ }^{9}$

Sistem JKN bertujuan untuk memaksimalkan pelayanan promotif dan preventif agar dapat mengurangi beban anggaran belanja kesehatan. ${ }^{10}$ Praktek di puskesmas memperlihatkan bahwa sistem JKN tidak terlalu mempengaruhi pelayanan promotif dan preventif yang sudah ada di puskesmas. ${ }^{11}$ Sistem JKN memilki program kendali mutu yang berlangsung dalam jangka waktu satu tahun sekali menggunakan standar ISO 9000 dari organisasi standar internasional. ${ }^{12}$ Sistem JKN memiliki kriteria dan program kendali mutu tersendiri yang berbeda dengan ISO 9000. Dokter puskesmas masih belum memahami tentang program kendali mutu yang berada di puskesmas.

Menurut Kementerian Kesehatan RI, proses sosialisasi sistem JKN kepada masyarakat dilakukan dalam jangka waktu 6 bulan pertama setelah implementasi sistem JKN pada tahun 2014, namun masih banyak masyarakat yang belum memahami tentang peraturan dalam sistem ini. ${ }^{13}$ Dokter puskesmas masih sering melakukan sosialisasi langsung kepada setiap pasien mengenai hak dan kewajibannya sehingga mengganggu pelayanan yang berlangsung di puskesmas.

Persepsi dokter puskesmas mengenai jumlah gaji kapitasi yang diterima dalam sistem JKN sudah merasa cukup, namun mengeluhkan tentang keterlambatan pembayaran yang terjadi. Dokter puskesmas tidak menerima gaji kapitasi dalam waktu satu bulan sekali, tetapi dalam waktu 2-3 bulan sekali. Solusi yang dilakukan di Yogyakarta adalah dengan menggunakan dana operasional talangan (reimburse), namun solusi tersebut masih dinilai kurang efektif. ${ }^{8}$ Kendala terhadap keterlambatan ini belum diketahui penyebab pastinya hingga kini. Masyarakat di setiap wilayah puskesmas belum sepenuhnya mendaftar menjadi peserta JKN, sehingga dokter puskesmas masih menerima pembayaran langsung (fee for service) dari pasien non-JKN. Perbandingan gaji kapitasi lebih besar dibandingkan gaji yang berasal dari peserta non-JKN atau non-kapitasi, sehingga dokter puskesmas mengeluhkan keterlambatan pembayaran kapitasi yang terjadi. Penerapan kapitasi mempengaruhi disiplin kerja dokter di puskesmas. Pemotongan gaji dilakukan sesuai dengan jumlah izin dokter puskesmas selama 1 bulan.

Sistem JKN mengatur puskesmas sebagai fasilitas kesehatan primer untuk mengendalikan angka rujukan. ${ }^{7}$ Dokter puskesmas hanya boleh merujuk pasien apabila terdapat indikasi dan keluhan pasien berada di luar kompetensi dokter puskesmas. ${ }^{9}$ Pada kenyataannya di puskesmas menunjukkan hal yang berkebalikan, yaitu jumlah rujukan yang semakin tinggi. Penelitian sebelumnya menyatakan bahwa karakteristik rujukan di rumah sakit belum berjalan sesuai dengan aturan jenjang sistem JKN. ${ }^{14}$ Angka rujukan yang meningkat disebabkan oleh jumlah kunjungan pasien penyakit kronis yang tinggi, sistem rujukan balik yang belum berjalan dengan baik, dan karakteristik pasien yang lebih mempercayai pengobatan yang dilakukan oleh dokter spesialis di rumah sakit. Permasalahan sistem rujukan berhubungan dengan sosialisasi kepada masyarakat yang minim sehingga masyarakat tidak mengetahui tentang peraturan sistem rujukan itu sendiri. Jumlah rujukan yang tinggi juga dapat menimbulkan tendensi saving money yang dilakukan oleh dokter puskesmas.

Potensi pendapatan yang diterima dokter puskesmas merupakan selisih dari nilai kapitasi yang didapat dengan jumlah kunjungan. Jumlah kunjungan pasien di puskesmas mengalami peningkatan karena banyak masyarakat yang sebelumnya tidak bisa untuk berobat karena kendala biaya menjadi terbebas dari biaya berobat dan meningkatnya jumlah pasien yang meminta rujukan ke rumah sakit. Semakin tinggi 
jumlah kunjungan pasien akan mengurangi nilai kapitasi yang dokter puskesmas terima. ${ }^{3}$ Program promotif dan preventif dalam sistem JKN berfungsi untuk meningkatkan tingkat kesehatan masyarakat, sehingga mengurangi jumlah kunjungan ke fasilitas kesehatan.

Komposisi jam kerja dokter puskesmas terbagi menjadi dua, yaitu $80 \%$ untuk pelayanan tatap muka seperti tindakan medis dan penyuluhan, $20 \%$ untuk pelayanan non-tatap muka seperti pengembangan pendidikan keprofesian dan administrasi. ${ }^{3}$ Sistem JKN tidak mempengaruhi jumlah jam kerja dokter di puskesmas. Secara umum, dokter puskesmas telah melakukan komposisi waktu kerja secara proporsional, namun terdapat beberapa pelayanan yang belum dijalankan dengan maksimal. Pelayanan tatap muka kunjungan rumah dan pelayanan non-tatap muka pengembangan pendidikan keprofesian belum dijalankan dengan maksimal.

Implementasi sistem JKN tidak terlalu mempengaruhi pelayanan gawat darurat 24 jam. Peserta JKN dengan keluhan tidak gawat darurat yang datang berobat di luar jam pelayanan normal tetap dilayani dengan pendekatan edukasi tentang syarat-syarat pengobatan di layanan gawat darurat. Peraturan mengenai pencairan dana kapitasi untuk operasional puskesmas (obat, bahan habis pakai, dan alat kesehatan) belum disahkan oleh Dinas Kesehatan. Menurut rancangan yang telah dilakukan oleh puskesmas, diperkirakan pencairan dana operasional akan sulit memenuhi kebutuhan operasional puskesmas. ${ }^{15}$

Secara umum, persepsi dokter puskesmas mengenaiperbandingan gaji kapitasiyang diterima dengan jumlah jam kerja yang diwajibkan sudah merasa cukup baik. Keterbatasan dalam penelitian ini adalah hanya dapat menggambarkan persepsi dokter puskesmas di kota Bandung terhadap sistem JKN sehingga tidak dapat digeneralisasi. Secara umum, dapat disimpulkan bahwa dokter puskesmas sudah cukup memahamiimplementasi sistem JKN, dilihat dari aspek pengetahuan tentang sistem JKN, sistem kapitasi, dan potensi pendapatan yang diperoleh. Kekurangan yang sering dikeluhkan mengenai sosialisasi yang masih minim dan pembayaran gaji kapitasi yang terlambat.

Saran dari penelitian ini adalah peningkatan sosialisasi dari pihak BPJS atau Dinas Kesehatan kepada tenaga medis dan masyarakat agar tidak mengganggu pelayanan di puskesmas dan dilakukan pengkajian ulang mengenai lama pembayaran gaji kapitasi dokter puskesmas. Penelitian ini diharapkan dapat menjadi acuan untuk penelitian serupa pada wilayah yang berbeda.

\section{Daftar Pustaka}

1. Peraturan Menteri Kesehatan No. 28 Tahun 2014 tentang Pedoman Pelaksanaan Program Jaminan Kesehatan Nasional (2014).

2. Peraturan Presiden No. 72 Tahun 2012 tentang Sistem Kesehatan Nasional, Pasal 1, Bab 5 no 173 (2012).

3. Soetono G, Kurtanty, Dien. Metode Membayar Dokter Layanan Primer Dalam Era JKN. Jakarta: Pengurus Besar Ikatan Dokter Indonesia; 2013.

4. Creswell JW. Research Design Pendekatan Kualitatif, Kuantitatif, dan Mixed. 3 ed. Yogyakarta: Pustaka Pelajar; 2014.

5. Muhammad A, Linda, Aryani. Hubungan antara persepsi terhadap organisasi dengan minat berorganisasi pada mahasiswa fakultas psikologi UIN Suska. Jurnal Psikologi. 2011;7(2):153.

6. C. WIlliam Keck G, A. Reed. The Curious Case of Cuba. American Journal of Public Health. 2012;102:13-22.

7. Yandrizal B, Anita, Hanni. Analisis Ketersediaan Fasilitas Kesehatan Dan Pemerataan Pelayanan Pada Pelaksanaan Jaminan Kesehatan Nasional Di Kota Bengkulu, Kabupaten Seluma, Dan Kabupaten Kaur. Jurnal Kebijakan Kesehatan Indonesia. 2014;03:103-12.

8. Sunarto. Sistem Pembiayaan dan Skema Kelembagaan Jaminan Kesehatan Daerah Kota Yogyakarta. Jurnal Kesehatan Masyarakat Nasional. 2011;5(6).

9. Asmaripa Ainy M, Nur Alam Fajar. Importance Performance Analysis Pelayanan Jaminan Sosial Kesehatan di Puskesmas Swakelola Pembina. Jurnal Kesehatan Masyarakat Nasional. 2012;7(3).

10. Diane R SM, and Elliott S. Fisher. Primary Care and Accountable Care - Two Essential Elements of Delivery-System Reform. The New England Journal of Medicine. 2009;361(24):2301-03.

11. Wiku Adisasmito P, Hasbullah Thabrany, dkk. Persepsi Stakeholder tentang Kompetensi Dokter di Layanan Kesehatan Primer. Majalah Kedokteran Indonesia. 2010;60(1).

12. Rangga AF. Penerapan Prinsip Manajemen Kualitas di Poli Umum Puskesmas Kecamatan Tebet Jakarta Selatan. Jurnal Kesehatan Masyarakat Nasional. 2009;3(4).

13. Rezky Kurnia Geswar N, Balqis. Kesiapan stakeholder dalam pelaksanaan program JKN di Kabupaten Gowa. Jurnal Administrasi dan Kebijakan Kesehatan. 2014;3(1):14-21.

14. Robby A HW, Nugraha S. Penilaian Rujukan Pasien Bersalin Peserta BPJS Kesehatan 
Aldi Harry Ramdani : Persepsi Dokter Puskesmas di Kota Bandung terhadap Implementasi Sistem Jaminan Kesehatan Nasional

di RSHS Berdasarkan Sistem Jaminan Kesehatan Nasional Periode 1 Oktober 31 Desember 2014. Prosiding Pendidikan Dokter 2014;2:995-99.

15. Aulia P. Polemik Kebijakan Integrasi
Jaminan Keshetan Daerah ke Sistem Jaminan Kesehatan Nasional. Jurnal Kesehatan Masyarakat andalas. 2014; 8(2):92-98. 